\title{
Effectiveness of Neuromuscular Electrical Stimulation on Neurological Pharyngeal Dysphagia
}

\author{
${ }^{1}$ Susmita Ghosh, ${ }^{2}$ Abhijit Das, ${ }^{3}$ Rajanikanta Pradhan, ${ }^{4}$ Bhaskar Dey, ${ }^{5}$ Jayanta Roy, ${ }^{6}$ Amitabha Roychoudhury
}

\section{ABSTRACT}

This study was done to find the effectiveness of neuromuscular electrical stimulation (NMES) over anterior neck muscles. Sixteen patients, age range 50 to 80 years with pharyngeal dysphagia of neurological origin were included for study. A similar age-matched control group of 16 patients was taken from medical records. Detailed history, clinical assessment, investigations that are a flexible endoscopic evaluation of swallowing (FEES) and videofluoroscopic study of swallowing (VFS) was done. Subjective response (percentage of total diet taken orally) and penetration-aspiration scale (PAS) score at the beginning of treatment were noted. NMES was given to the study group along with swallow therapy. The suprahyoid muscles were stimulated regularly for 2 weeks. The reassessment was done after 2 weeks. The control group received only swallow therapy but no NMES. The results of the control group were also noted. Changes in the percentage of the total quantity of diet taken orally were asked. Upgradation in PAS score was assessed using FEES and VFS. The satisfactory improvement was found within 2 weeks in the study group. This took about 2 months in the control group. Hence, NMES was found to be an effective tool for dysphagia management.

Keywords: Endoscopic evaluation of swallowing, Neurological, Neuromuscular electrical stimulation, Penetration-aspiration scale, Pharyngeal dysphagia, videofluoroscopic study of swallowing.

How to cite this article: Ghosh S, Das A, Pradhan R, Dey B, Roy J, Roychoudhury A. Effectiveness of Neuromuscular Electrical Stimulation on Neurological Pharyngeal Dysphagia. Int J Phonosurg Laryngol 2018;8(1):31-35.

\section{Source of support: Nil}

Conflict of interest: None

\footnotetext{
${ }^{1}$ Consultant, ${ }^{2,6} \mathrm{HOD},{ }^{3,4}$ Speech Swallow Pathologist ${ }^{5}$ Director

1,3,6 Department of Otolaryngology, Amri Hospital, Mukundapur, Kolkata, West Bengal, India

${ }^{2,4}$ Department of Neuro Rehab, Amri Hospital, Mukundapur, Kolkata, West Bengal, India

${ }^{5}$ Department of Neurology, Amri Hospital, Mukundapur, Kolkata, West Bengal, India

Corresponding Author: Susmita Ghosh, Consultant, Department of Otolaryngology, Amri Hospital, Mukundapur, Kolkata, West Bengal, India, e-mail: susmita_ent@rediffmail. com
}

\section{INTRODUCTION}

Neuromuscular electrical stimulation (NMES) is transcutaneous galvanic stimulation in small amounts of the motor nerve endings that innervate muscles beneath the skin. It stimulates the central nervous system (CNS) stimulation and causes involuntary muscle contraction ${ }^{1}$ in patients with CNS abnormalities but intact peripheral nerve function. ${ }^{2}$ This effect was first established by Luigi Galvani in 1761. It keeps the muscle function intact and recruits more muscle fibers, thus, helps to strengthen muscles and prevents atrophy. ${ }^{3,4}$ Hence it causes quick re-education of CNS by stimulating the sensory pathways. NMES has been clinically used for the treatment of facial palsy. ${ }^{5}$ It is also used in vocal fold palsy. Other fields of use are in sports medicine, ${ }^{6}$ after knee arthroplasty, in spastic diplegic cerebral palsy cases. NMES received FDA approval in 2002 for use in dysphagia in the laryngeal neck region. It was marketed as VitalStim (Chattanooga Group Hixon TN). The clinical uses in dysphagia mainly neurological (CVA, degenerative disease, geriatric patients), post-radiotherapy fibrosis, and post head and neck surgery with reconstruction. NMES is used in dysphagia as it is a non-invasive method and decreases recovery time. This stimulates the hyolaryngeal muscles and causes faster improvement in Laryngeal elevation, which is needed for airway protection. This prevents aspiration increasing swallow safety. It also helps better functioning of the pharyngeal pump and combined with traditional swallow exercise it speeds up recovery time. ${ }^{7-9}$

Contraindications are an active neoplasm, the presence of implantable electronic devices, history of seizures, the presence of infection, secretions, bleeding areas, placement of electrodes over carotid sinus, during radiation and chemotherapy, pregnancy, patients on ventilators and with metal tracheotomy tubes. ${ }^{10}$ There are some existing studies in the Indian scenario. Mittal et al. in 2015 observed that transcutaneous NMES might help patients with mild to moderate dysphagia. Hence it could be used as a technique to improve the speed of triggering the pharyngeal swallow. ${ }^{11}$ In a case report in 2014, Gupta and Banerjee ${ }^{12}$ used NMES for recovery of dysphagia in cases of lateral medullary stroke. A significant effect of electrical stimulation of the masseter muscle in early stroke patients with dysphagia was observed 
by Mehendiratta et al. in a recent study in $2017 .{ }^{13}$ The aim of our study is to find the effectiveness of NMES on anterior neck muscle strengthening in neurology patients with pharyngeal dysphagia. We used the Penetrationaspiration Scale score and percentage of total diet taken orally as our evaluation parameters.

\section{MATERIALS AND METHODS}

Total 16 patients of isolated pharyngeal dysphagia of neurological origin were selected from cases of Neuro Rehab Unit of a tertiary care hospital. Age of the patients ranged 50 to 82 years (average age 62.4 years). The study was conducted over a period of one year (January to December 2017). The pre-stimulation assessment was done through history, clinical examination. Flexible endoscopic evaluation of swallowing (FEES) was performed in all patients. Videofluoroscopic assessment of swallowing (VFS) was also carried out unless there was a contraindication. The penetration-aspiration scale (PAS) score was determined (Table1). PAS score was used for objective evaluation. The penetration-aspiration scale in Table 1 is an 8 point scoring system. Score 1 means no penetration or aspiration, 2 to 5 represents penetration of different grades and 6 to 8 , aspiration in increasing severity. The patient and relatives were asked about the amount of food the patient used to take before the onset of dysphagia. Then they were asked to quantify how much food the patient was able to take per month after the onset of a swallowing disorder. This percentage of total diet taken orally was taken as a subjective parameter. The treatment protocol was decided in a multidisciplinary setting involving Otolaryngologist, Speech Language Pathologist (SLP) and Neurophysician. The dual channel neuromuscular electrical stimulator (Model: VitalStim Plus. Make: Chattanooga) was used. The electrodes were placed on both

Table 1: Penetration-aspiration scale (PAS)

\begin{tabular}{lcl}
\hline Category & Score & Description \\
\hline $\begin{array}{l}\text { No } \begin{array}{l}\text { penetration } \\
\text { or aspiration }\end{array} \\
\text { Penetration }\end{array}$ & 2 & Bolus does not enter the airway. \\
& 3 & $\begin{array}{l}\text { Bolus enters the airway, remains above } \\
\text { the vocal folds, no residue. } \\
\text { Bolus remains above the vocal folds, } \\
\text { visible residue remains. }\end{array}$ \\
& 4 & $\begin{array}{l}\text { Bolus contacts vocal folds, no residue. } \\
\text { Bolus contacts vocal folds, visible } \\
\text { residue remains. }\end{array}$ \\
& 6 & $\begin{array}{l}\text { Bolus passes glottis, no subglottic } \\
\text { residue visible. } \\
\text { Bolus passes glottis, visible subglottic } \\
\text { residue despite patient's response. } \\
\text { Bolus passes glottis, visible subglottic } \\
\text { residue, absent patient response. } \\
\text { Woods et al. 1996 }\end{array}$ \\
\hline
\end{tabular}

sides over the suprahyoid muscles (Montage Placement 2a). NMES was given for 2 weeks at 2 to $3 \mathrm{~mA}, 60$ minutes daily. The duration and intensity of current were readjusted during therapy. This was done accordingly as the muscles regained strength and retrained. The patients' subjective response to the stimulation was also taken into consideration. During the administration of NMES swallow therapy was also given. Each patient was individualized and made to perform different exercises such as chin tuck, head turn. After 2 weeks of treatment, a reassessment was done using the same method. PAS score was assessed. Initially, the patient oral intake was reduced to $10-20 \%$ of total diet, in many swallows was not safe and all CVA patients were on nasogastric tube feed. Post-therapy improvement in the amount of dietary intake was noted (subjective response). A retrospective case note study of 16 age-matched patients of neurological pharyngeal dysphagia was done. These patients were also assessed in the same way. History, clinical examination, noting the amount of dietary intake; FEES, VFS, and determination of PAS score were carried out. Similar swallow therapy was given but no NMES was administered. This was taken as our control group and their clinical improvement at 2 weeks was noted.

\section{RESULTS}

The spectrum of diagnosis of sixteen patients in the study group is depicted in Table 2 and those of the control group in Table 3. Table 2 shows the pre and post-therapy data of the study group. There was a total of 16 patients with neurological pharyngeal dysphagia (cerebrovascular

Table 2: Pre- and post-therapy data of study group

\begin{tabular}{|c|c|c|c|c|c|}
\hline Patient & $\begin{array}{l}\text { Dise- } \\
\text { ase }\end{array}$ & $\begin{array}{l}\text { Pre- } \\
\text { therapy } \\
\text { PAS } \\
\text { score }\end{array}$ & $\begin{array}{l}\text { Pre- } \\
\text { therapy } \\
\text { Dietary } \\
\text { intake }\end{array}$ & $\begin{array}{l}\text { Post- } \\
\text { therapy } \\
\text { PAS } \\
\text { score }\end{array}$ & $\begin{array}{l}\text { Post- } \\
\text { therapy } \\
\text { Dietary } \\
\text { intake }\end{array}$ \\
\hline 1. $79 \mathrm{yrs} / \mathrm{M}$ & CVA & 6 & $10 \%$ & 2 & $50 \%-60 \%$ \\
\hline 2. $75 \mathrm{yrs} / \mathrm{F}$ & MND & 5 & $20 \%$ & 3 & $40 \%-50 \%$ \\
\hline 3. $50 \mathrm{yrs} / \mathrm{M}$ & CVA & 5 & $20 \%$ & 2 & $50 \%-60 \%$ \\
\hline 4. $55 \mathrm{yrs} / \mathrm{M}$ & CVA & 5 & $20 \%$ & 2 & $50 \%-60 \%$ \\
\hline 5. $74 \mathrm{yrs} / \mathrm{M}$ & CVA & 6 & $10 \%$ & 3 & $40 \%-50 \%$ \\
\hline 6. $63 \mathrm{yrs} / \mathrm{F}$ & PD & 6 & $10 \%$ & 3 & $40 \%-50 \%$ \\
\hline 7. $48 \mathrm{yrs} / \mathrm{M}$ & MND & 5 & $20 \%$ & 2 & $50 \%-60 \%$ \\
\hline 8. $44 \mathrm{yrs} / \mathrm{M}$ & CVA & 6 & $10 \%$ & 3 & $40 \%-50 \%$ \\
\hline 9. $68 \mathrm{yrs} / \mathrm{F}$ & CVA & 5 & $20 \%$ & 2 & $50 \%-60 \%$ \\
\hline 10. $57 \mathrm{yrs} / \mathrm{M}$ & LMS & 6 & $20 \%$ & 2 & $50 \%-60 \%$ \\
\hline 11. $63 \mathrm{yrs} / \mathrm{M}$ & LMS & 6 & $10 \%$ & 2 & $50 \%-60 \%$ \\
\hline 12. $59 \mathrm{yrs} / \mathrm{M}$ & CVA & 5 & $20 \%$ & 2 & $50 \%-60 \%$ \\
\hline 13. $80 \mathrm{yrs} / \mathrm{F}$ & CVA & 5 & $20 \%$ & 2 & $50 \%-60 \%$ \\
\hline 14. $79 \mathrm{yrs} / \mathrm{M}$ & CVA & 5 & $10 \%$ & 2 & $50 \%-60 \%$ \\
\hline 15. $55 \mathrm{yrs} / \mathrm{M}$ & PD & 6 & $20 \%$ & 2 & $50 \%-60 \%$ \\
\hline 16. $59 \mathrm{yrs} / \mathrm{F}$ & CVA & 5 & $10 \%$ & 2 & $50 \%-60 \%$ \\
\hline
\end{tabular}

CVA $=$ cerebrovascular accident, $\mathrm{MND}=$ motor neuron disease, $\mathrm{PD}$ = Parkinsons Disease, LMS = Lateral medullary syndrome. 


\begin{tabular}{|c|c|c|c|c|c|}
\hline Patient & Disease & $\begin{array}{l}\text { Pre- } \\
\text { therapy } \\
\text { PAS } \\
\text { score }\end{array}$ & $\begin{array}{l}\text { Pre- } \\
\text { therapy } \\
\text { Dietary } \\
\text { intake }\end{array}$ & $\begin{array}{l}\text { Post- } \\
\text { therapy } \\
\text { PAS } \\
\text { score }\end{array}$ & $\begin{array}{l}\text { Post- } \\
\text { therapy } \\
\text { dietary } \\
\text { intake }\end{array}$ \\
\hline 1. $65 \mathrm{yrs} / \mathrm{F}$ & MND & 5 & $20 \%$ & 4 & $30 \%-40 \%$ \\
\hline 2. $58 \mathrm{yrs} / \mathrm{M}$ & CVA & 5 & $20 \%$ & 3 & $40 \%-50 \%$ \\
\hline 3. $78 \mathrm{yrs} / \mathrm{F}$ & PD & 5 & $20 \%$ & 3 & $40 \%-50 \%$ \\
\hline 4. $75 \mathrm{yrs} / \mathrm{M}$ & CVA & 6 & $10 \%$ & 4 & $30 \%-40 \%$ \\
\hline 5. $54 \mathrm{yrs} / \mathrm{M}$ & CVA & 6 & $10 \%$ & 3 & $40 \%-50 \%$ \\
\hline 6. $72 \mathrm{yrs} / \mathrm{F}$ & CVA & 6 & $10 \%$ & 4 & $30 \%-40 \%$ \\
\hline 7. $54 \mathrm{yrs} / \mathrm{M}$ & CVA & 5 & $20 \%$ & 3 & $40 \%-50 \%$ \\
\hline 8. $82 \mathrm{yrs} / \mathrm{F}$ & CVA & 5 & $20 \%$ & 3 & $40 \%-50 \%$ \\
\hline 9. $62 \mathrm{yrs} / \mathrm{M}$ & $\mathrm{PD}$ & 5 & $20 \%$ & 3 & $40 \%-50 \%$ \\
\hline 10. $60 \mathrm{yrs} / \mathrm{F}$ & CVA & 5 & $20 \%$ & 3 & $40 \%-50 \%$ \\
\hline 11. $78 \mathrm{yrs} / \mathrm{M}$ & CVA & 6 & $10 \%$ & 4 & $30 \%-40 \%$ \\
\hline 12. $60 \mathrm{yrs} / \mathrm{M}$ & LMS & 6 & $10 \%$ & 3 & $40 \%-50 \%$ \\
\hline 13. $46 \mathrm{yrs} / \mathrm{M}$ & CVA & 5 & $20 \%$ & 3 & $40 \%-50 \%$ \\
\hline 14. $59 \mathrm{yrs} / \mathrm{M}$ & MND & 5 & $20 \%$ & 4 & $30 \%-40 \%$ \\
\hline 15. $49 \mathrm{yrs} / \mathrm{M}$ & LMS & 6 & $10 \%$ & 3 & $40 \%-50 \%$ \\
\hline 16. $67 \mathrm{yrs} / \mathrm{F}$ & CVA & 5 & $20 \%$ & 4 & $30 \%-40 \%$ \\
\hline
\end{tabular}

$\mathrm{CVA}=$ cerebrovascular accident, $\mathrm{MND}=$ motor neuron disease, $\mathrm{PD}$ $=$ Parkinsons Disease. LMS $=$ Lateral medullary syndrome.

accident, motor neuron disease, Parkinson's disease, lateral medullary syndrome). Initially, their PAS score was between 6 and 5 . They could take only 10 to $20 \%$ of their total diet orally with difficulty. After 2 weeks of neuromuscular electrical stimulation added to exercises, their PAS score could be upgraded to 3 or 2 , and, they could take 50 to 605 of their total diet orally and safely. Table 3 represents the spectrum of 16 patients of the retrospective control group. Here again, their pre-therapy PAS score was between 6 and 5 , and they could hardly take 10 to $20 \%$ of their total dietary amount orally. They were given only exercises. No NMES was given to these patients. After 2 weeks reassessment showed PAS score between 4 and 3 , and their oral dietary intake increased to 30 to 40 $\%$ of the total amount they used to take. Graphs 1 and 2 are the graphical representation of pre and post therapy

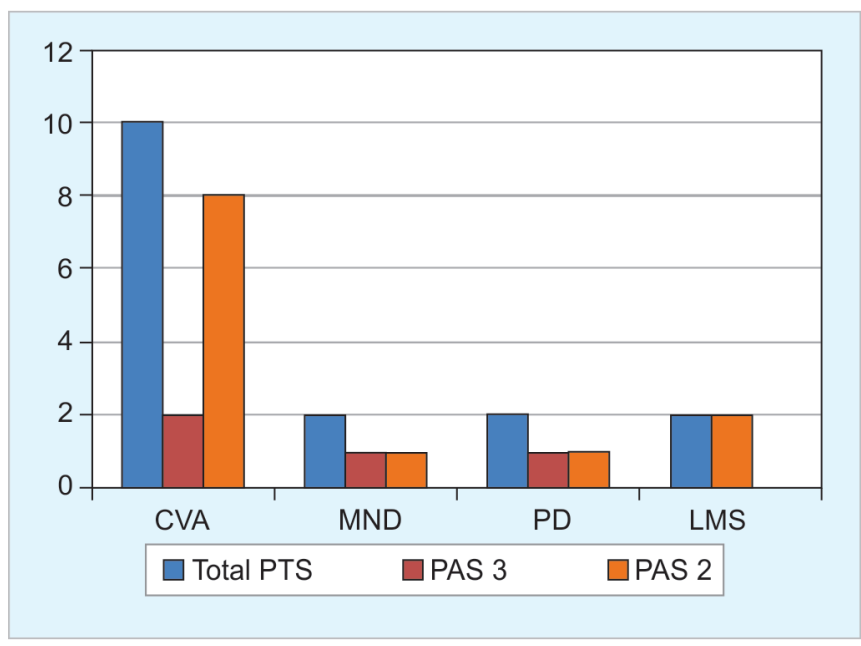

Graph 1: Post-therapy results (PAS score)-study group

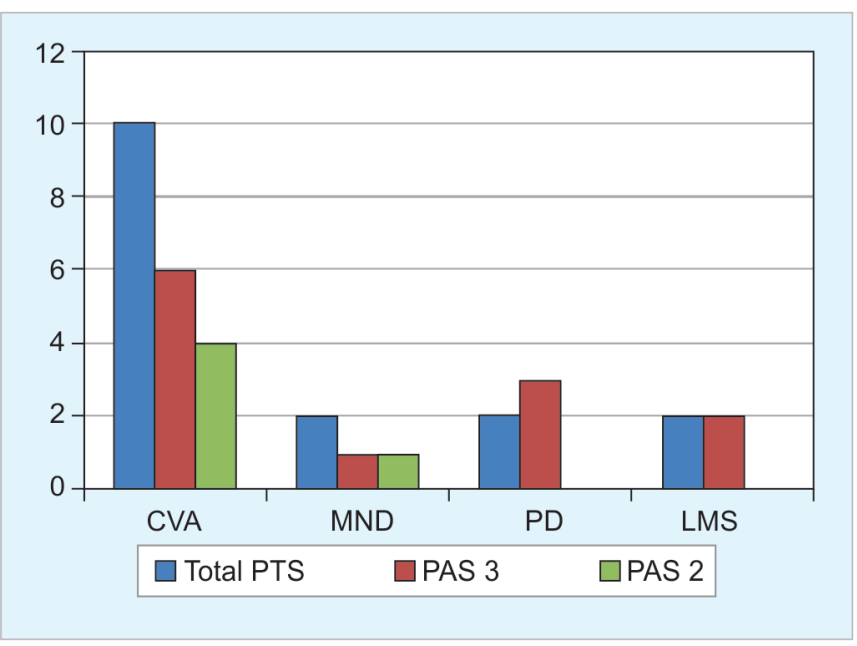

Graph 2: Post-therapy results (PAS score)-control group

changes in PAS score in both the groups assessed. Graph 1 is a bar diagram showing the improvement in PAS score after NMES. Of total 10 CVA patients PAS improved to 2 in 8 , and 3 in 2 patients. Of the MND cases, 1 showed score 2 and the other 3 after treatment. It was the same for PD cases. Patients of LMS were 2 in number, and both after 2 weeks of NMES, showed an improvement in PAS score from 6 to 2. The control group PAS score improvement post-therapy without NMES, as a bar diagram presentation in Graph 2. It shows, of 10 CVA cases, 4 had PAS score 4 and 6 had score 3 . The 2 MND cases, one had score 4 and the other 3. Both PD patients had a post-therapy score of 3 after 2 weeks as also the 2 LMS cases. Table 1 , as already stated earlier shows the PAS score (Woods et al. 1996) we used for objective evaluation of patients using FEES and VFS before and after management. The change in the percentage of total diet that could be taken orally without aspiration was the standard of subjective improvement of patients. Figures 1 and 2 that represent the post-therapy percentage of total diet that could be taken orally without aspiration in the study and control groups respectively. Figure 1 is a pie chart showing posttherapy oral dietary intake in the study group. Hereafter 2 weeks of NMES, of the total 16 cases, 12 could take 50 to $60 \%$ of their diet safely, orally and 4 could take 40 to $50 \%$. Figure 1 is the pie chart representation of the control group. This chart highlights that after 2 weeks of exercise only, without any NMES, from the initial amount of 10 to $20 \%$, in 10 patients the amount of diet they could take orally was 40 to $50 \%$ of the total amount. In the remaining 6 cases, it was 30 to $40 \%$ of the total amount.

\section{DISCUSSION}

Dysphagia is described as swallowing disorder usually resulting from a neurological or physical impairment of oral, pharyngeal or oesophageal mechanisms. The 


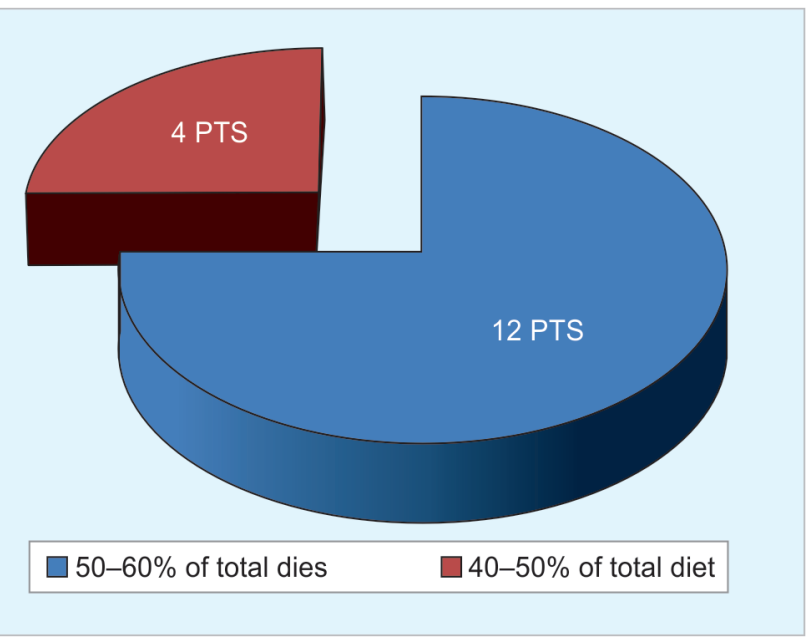

Fig. 1: Post-therapy oral dietary intake-study group

difficulty with swallowing may have life-threatening consequences and can lead to an impaired quality of life. This was stated in Sue Pownall's chapter on Electrical Stimulation for the Treatment of Dysphagia. ${ }^{14}$ Our patient group had neurological disorders where the pharyngeal phase of swallowing was affected. The condition affected their general health due to malnutrition as well as life quality because of difficulty in oral intake. From a clinical point of view, we were more concerned with the chances of aspiration that could affect survival and hence had to assure safe swallowing. Pownall also stated ${ }^{14}$ that electrical stimulation has recently become of interest to clinicians working with people presenting with dysphagia due to its rehabilitation potential, especially for pharyngeal stage swallow disorders. This is also the key interest in our study. Since the experiment of Luigi Galvani, it has been established that small amounts of electrical stimulation cause contraction of muscle fibers. Types 1 and 2 muscle fibers are mainly recruited. This is the principle behind NMES. It has been widely used in different areas as sports medicines, facial palsy. ${ }^{15}$ In recent years NMES has come to play a significant role in oropharyngeal dysphagia after FDA approval in 2002. We used it in our patients of pharyngeal dysphagia of neurological origin. Bulow et al. in 2008, ${ }^{16}$ found statistically significant improvement in combining NMES with traditional therapy (TT). This conforms to our study results. They used dual channel pharyngeal stimulation like us. Bulow et al. selected only post-stroke dysphagia patients. Our study included different neurology patients as cerebrovascular accident, Parkinson disease, motor neuron disease, lateral medullary syndrome. But all had pharyngeal dysphagia. We used both FEES and VFS along with a quantity of oral intake for pre and post stimulation evaluation. Whereas only VFS and nutritional status were taken to consideration by Bulow et al. Carnaby-Mann et al. did a meta-analysis of 7 studies which showed positive

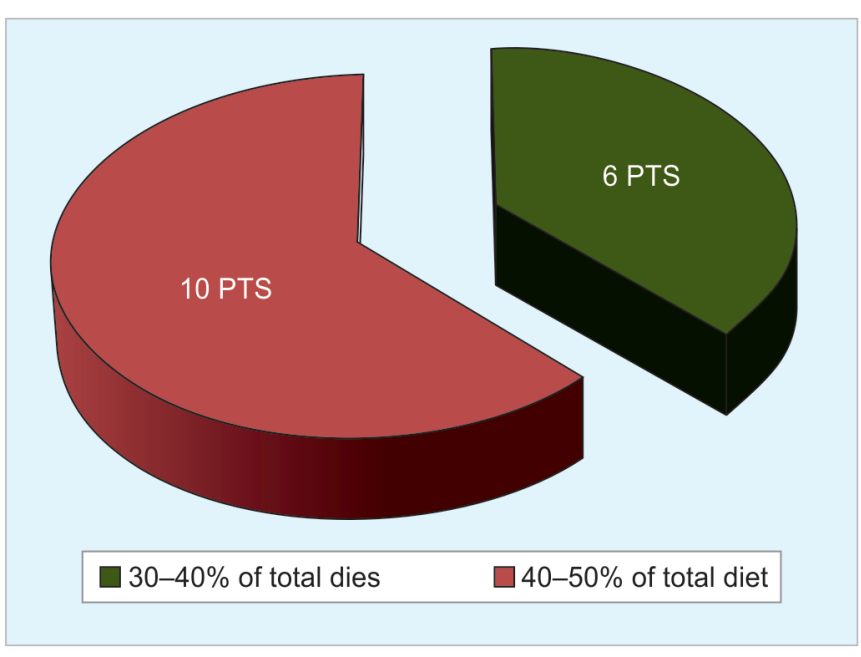

Fig. 2: Post-therapy oral dietary intake-control group

effects of NMES on swallowing. ${ }^{17}$ They concluded that their result was significant, where the study was small. Hence they felt the need for more research on this aspect. In the study we did, there were 16 patients where we combined traditional therapy with NMES. Our retrospective control group also consisted of 16 patients. This was also a small study. But there was a significant improvement in using NMES, in our study too.

\section{CONCLUSION}

Hence NMES is an effective tool in the management of pharyngeal dysphagia of neurological origin. Our study also confirms that adding NMES results in superior and faster outcome compared to traditional swallow therapy in neurological pharyngeal dysphagia.

\section{CLINICAL RELEVANCE}

Neurological pharyngeal dysphagia can be treated effectively with NMES to achieve superior and faster recovery. NMES should be added to the armamentarium of any swallowing clinic, dealing with neurological pharyngeal dysphagia.

\section{REFERENCES}

1. Azman MF, Azman AW. The effect of electrical stimulation in improving muscle tone (clinical). InIOP Conference Series: Materials Science and Engineering 2017 Nov (Vol. 260, No. 1, p. 012020). IOP Publishing.

2. Sheffler LR, Chae J. Neuromuscular electrical stimulation in neurorehabilitation. Muscle \& Nerve: Official Journal of the American Association of Electrodiagnostic Medicine. 2007 May;35(5):562-590.

3. Press JM, Bergfeld DA. Physical Modalities. Clinical Sports Medicine: Medical Management and Rehabilitation. 2007:207.

4. Doucet BM, Lam A, Griffin L. Neuromuscular electrical stimulation for skeletal muscle function. The Yale journal of biology and medicine. 2012 Jun;85(2):201.

5. Choi JB. Effect of neuromuscular electrical stimulation on facial muscle strength and oral function in stroke patients with facial 
palsy. Journal of physical therapy science. 2016;28(9):25412543.

6. Lake DA. Neuromuscular electrical stimulation. Sports medicine. 1992 May 1;13(5):320-336.

7. Frost J, Robinson HF, Hibberd J. A comparison of neuromuscular electrical stimulation and traditional therapy, versus traditional therapy in patients with longstanding dysphagia. Current opinion in otolaryngology \& head and neck surgery. 2018 Jun 1;26(3):167-173.

8. Poorjavad M, Talebian Moghadam S, Nakhostin Ansari N, Daemi M. Surface electrical stimulation for treating swallowing disorders after stroke: a review of the stimulation intensity levels and the electrode placements. Stroke research and treatment. 2014;2014.

9. Moe JH, Post HW. Functional electrical stimulation for ambulation in hemiplegia. The Journal-lancet. 1962 Jul;82:285-288.

10. Nussbaum EL, Houghton P, Anthony J, Rennie S, Shay BL, Hoens AM. Neuromuscular Electrical Stimulation for Treatment of Muscle Impairment: Critical Review and Recommendations for Clinical Practice. Physiotherapy Canada. 2017;69(5):1-76.
11. Mittal R, Mishra AK, Nilakantan A. Therapeutic interventions by speech language pathologist in managing adult dysphagia: An evidence based review. Journal of Laryngology and Voice. 2015 Jan 1;5(1):11.

12. Gupta H, Banerjee A. Recovery of dysphagia in lateral medullary stroke. Case reports in neurological medicine. 2014.

13. Mehndiratta MM, Gupta P, Kaur M. The effect of sensory-level electrical stimulation of the masseter muscle in early stroke patients with dysphagia. Neurology India. 2017 Jul 1;65(4):743.

14. Majid A. Electroceuticals. Springer; 2017, p. 137-156.

15. American Speech-Language-Hearing Association. Membership Survey summary report: Number and type of responses. Rockville, MD: Author. 2009.

16. Bülow M, Speyer R, Baijens L, Woisard V, Ekberg O. Neuromuscular electrical stimulation (NMES) in stroke patients with oral and pharyngeal dysfunction. Dysphagia. 2008 Sep 1;23(3):302-309.

17. Carnaby-Mann GD, Crary MA. Examining the evidence on neuromuscular electrical stimulation for swallowing: a metaanalysis. Archives of Otolaryngology-Head \& Neck Surgery. 2007 Jun 1;133(6):564-571. 